Visítanos en:

https://journal.poligran.edu.co/index.php/poliantea

\title{
NUEVAS CONSTRUCCIONES DE GÉNERO
}

\author{
Docente \\ Cristian Ivan Giraldo Leon \\ cgiraldo@poligran.edu.co
}

Estudiantes

Laura Camila Marulanda

Stefanny Andrea Bernal Bernal

Sindy Tatiana Salinas Pérez

Miryam Gabriela Hernandez Acuña

Isabella Tapia Aguiar

Edwin Fernando Porras Porras

Institución universitaria Politecnico Grancolombiano.

Programa de psicología
Indagaciones sobre

Feminismo y Género

El trabajo del semillero se ha enfocado en indagar desde la perspectiva de género, concepto entendido como una construcción social la cual se teje de manera histórica y que se va modificando según los cánones sociales, morales y estéticos de cada época y generación (Gambas, 2008). Las y los integrantes hemos iniciado nuestras búsquedas desde los relatos personales y luego revisando artículos, libros, conferencias sobre la historia del feminismo, tanto de la primera, como de la segunda y tercera ola, para poder acercarnos al movimiento de la cuarta ola, representada por el movimiento de reivindicación de los derechos sexuales y reproductivos, la reglamentación sobre el aborto y los feminicidios. Estas dos búsquedas son relevantes, por que sin el relato personal, el estudio perdería el soporte de la vivencia, es decir, el comprender que el ser mujeres y ser hombres no es una figura unificada y eterna, si no por el contrario un mito que cae ante el sentimiento de no ser real para todas y todos, como bien lo hemos manifestado en múltiples encuentros y es que no es lo mimos ser mujer, heterosexual y blanca a ser negra, prostituta y lesbiana (realizamos un paréntesis para denotar que blanca y negra, también son denominaciones muy propias de los textos clásicos de género estado - unidenses y europeos, pero sin abordar a las mujeres y los hombres propios del mestizaje).

Desde ese lugar de vivencia, el segundo componente que es el histórico, nos ha remitido a plantear que el género fue pensado como diferente a lo sexual desde hace mucho tiempo, por ejemplo por medio de las luchas de mujeres como Olimpia de Gouges, quien al reclamar "los derechos de la mujer y la ciudadana" fue guillotinada, o por el movimiento sufragista inglés y norteamericano a la cabeza de Elizabeth Cadi Stanton,

\section{POLIANTEA}

Vol. 15. No. 26. Año 2020 | Enero - junio de 2020 | ISSN 1794-3159 - E ISSN: 2145-3101 
quienes se unen a la lucha contra la esclavitud, logrando primero en esta unión de ideales que se acabe con esta, pero sin que se les del derecho al voto a las mujeres si no muchos años más tarde (Gambas, 2008).

De estas discusiones aparecieron dos propuestas de investigación: una revisión de literatura denominada: Construcciones de género y sexualidad en Colombia y una investigación aplicada

llamada: Representaciones sociales que se construyen entorno a la violencia de género en la familia por parte de los y las estudiantes del Politécnico Grancolombiano. Las cuales se encuentran en proceso de elaboración conceptual, la primera en fase de revisión final y la segunda en integración teórica para ejecución.

El interés del semillero es seguir avanzando desde lo académico, pero también desde la acción social, de mostrar que las luchas del feminismo siguen presentes $y$ que a pesar de los cambios supuestos de la novedad, todavía la lucha por la igualdad de derechos y la equidad, requiere no solo la teorización, sino la incorporación a la acción cotidiana, donde no quede ninguna duda sobre la diferencia entre lo que se denomina sexo biológico y aquello que es marcado por los estándares sociales y culturales de cada región, y que se experimenta en el cuerpo desde la obediencia y/o la resistencia, siendo la función de lo académico, que es donde emerge el semillero, servir de motor de lucha a favor de la diferencia, la igualdad, la equidad y la no violencia en sus diferentes formas.

Referencia

Gamba, S. (2008). Feminismo: historia $y$ corrientes. Publicado en Mujeres en Red. El periódico feminista. Recuperado de: te.gob.mx/genero/media/pdf /de3d6e5ea68e124.pdf

\section{POLIANTEA}

